\title{
Safety Profile and Efficacy of Tranexamic Acid on Haemorrhage during and after the Caesarean Section
}

\author{
Sudha Rani ${ }^{1}$, Arjumand Bano르, Mounika Reddy ${ }^{3}$ \\ 1, 2, 3 Department of Obstetrics and Gynaecology, Chalmeda Ananda Rao \\ Institute of Medical Sciences, Bommakal, Karimnagar, Telangana, India.
}

\section{ABSTRACT}

\section{BACKGROUND}

The interlink between Caesarean section, intraoperative and postoperative bleeding is well understood. Post-partum haemorrhage is one of the major causes of maternal morbidity and mortality. Tranexamic acid is a synthetic analogue of the amino acid lysine and its action is to reduce blood loss. Both antepartum and postpartum haemorrhage $(\mathrm{PPH})$ are being treated by tranexamic acid extensively. The aim of the study is to evaluate the safety and efficacy of tranexamic acid given intravenously for reducing the intraoperative and postoperative blood loss in lower segment Caesarean section.

\section{METHODS}

In this randomised, placebo-controlled, open-label study, 100 pregnant women undergoing elective Caesarean section were selected in random pattern and divided into control and study group of 50 patients each, in the Department of Obstetrics and Gynaecology in Chalmeda Anand Rao Institute of Medical Sciences from January 2019 to January 2020. The study group of 50 subjects were given $1 \mathrm{~g}$ of tranexamic acid intravenously (IV) and the control group of 50 subjects were given IV $5 \%$ dextrose. All the pregnant women received 10 units of oxytocin following delivery.

\section{RESULTS}

Based on the results, mean of the total blood loss in the study group was $30 \%$ less than the control group. And also, a significant difference was observed in the haemoglobin concentration of the two groups, i.e., the study group had less difference in their preoperative and postoperative $\mathrm{Hb}$ values compared to the control group. No significant difference was found in the two groups regarding other parameters like systolic and diastolic blood pressure (BP), heart rate, prothrombin time (PT), activated partial thromboplastin time (aPTT). In our study, no side effects were statistically noted in both the groups.

\section{CONCLUSIONS}

Data analysis of our study suggests that, a safe dose of IV tranexamic acid prior to Caesarean section has an effective role in reducing blood loss without causing any side effects.

\section{KEY WORDS}

Tranexamic Acid, Anti-fibrinolytics, Caesarean Delivery, Postpartum Haemorrhage
Corresponding Author: Dr. Mounika Reddy, Polt. No - 473/D,

Road No - 87,

Jubilee Hills,

Hyderabad - 500033,

Telangana, India.

E-mail:

monicamohanakumar34@gmail.com

DOI: $10.14260 /$ jemds/2021/48

How to Cite This Article:

Rani S, Bano A, Reddy BM. Safety profile and efficacy of tranexamic acid on haemorrhage during and after the Caesarean section.J Evolution Med Dent Sci 2021;10(04):222-226,

$10.14260 /$ jemds/2021/48

Submission 27-09-2020,

Peer Review 25-11-2020,

Acceptance 03-12-2020,

Published 25-01-2021.

Copyright (c) 2021 Sudha Rani et al. This is an open access article distributed under Creative Commons Attribution License [Attribution 4.0 International (CC BY 4.0)] 


\section{BACKGROUND}

Worldwide about 530,000 maternal deaths occur annually due to pregnancy and childbirth. One of the most important reason of maternal mortality is the post-partum" bleeding". ${ }^{1}$ Caesarean section has many complications compared to that of vaginal delivery. Nearly $20 \%$ of these complications comprise of primary and secondary haemorrhage. Every year $1-2 \%$ of pregnant women die due to postpartum haemorrhage. ${ }^{2}$ Postpartum haemorrhage is defined as the blood loss of $500 \mathrm{~mL}$ or more after normal vaginal delivery or $>1000 \mathrm{~mL}$ following Caesarean "section (CS)".3 In immunocompromised and ill patients minimal blood loss of $200 \mathrm{~mL}$ is considered fatal.

Haemorrhage after delivery can be managed by administration of drugs like oxytocin, misoprostol, methylergonovine and anti-fibrinolytic agents such as tranexamic acid, aprotinin, epsilon amino caproic acid and also by blood transfusions. If these measures fail to control the haemorrhage, then hysterectomy is "done".4,5 Tranexamic acid is an anti "fibrinolytic drug,"6 and is a synthetic derivative of amino acid lysine, due to its high affinity for lysine, it blocks the binding of plasmin to the plasminogen molecule and its degradation to fibrin. World Health Organization (WHO) has passed the recent guidelines on administration of tranexamic acid for management of PPH if uterotonics and oxytocic drugs were ineffective to halt the bleeding and also to abort the complications of "hysterectomy". 7

The aim of our study is to assess the safety and efficacy of intravenous tranexamic acid (TXA) on haemorrhage during and after Caesarean section.

\section{METHODS}

This a prospective randomised, placebo-controlled, openlabelled clinical study, conducted from January 2019 till January 2020. The study was approved by institutional ethics committee (IEC) Reg. No. CAIMS/01/IEC/2020/010. Written and informed consent was taken from the patients.

The study was conducted on primi and multi para, clinically a free singleton pregnant woman, 18 - 35 years old, between 37 - 40 weeks of gestation, planned for elective Caesarean section with normal parameters.

Initially 113 women were admitted for elective Caesarean section, among them 10 pregnant women were excluded as 6 women set into spontaneous labour and had normal vaginal delivery and 4 women underwent emergency lower segment Caesarean section (LSCS) as 2 of them had scar tenderness and other 2 had fetal distress. Among the remaining 103 pregnant women, 3 of them were not willing to give consent. Finally, 100 women who fulfilled the inclusion criteria were allocated for the study.

\section{Inclusion Criteria}

1. Full term primi or multigravida with free singleton pregnancy.
2. Cephalic or abnormal presentation.

\section{Exclusion Criteria}

1. Medical problems involving brain, heart, kidney, liver and blood disorders.

2. History of thromboembolic disorders, symptoms of deep vein thrombosis, varicose veins.

3. History of any previous pregnancy related complications like severe preeclampsia, intrauterine growth restriction (IUGR), abnormal placenta, gestational diabetes mellitus (GDM), poly hydramnios and multiple pregnancy.

4. Any allergic reactions to TXA.

\section{Laboratory Examination}

1. Haemoglobin, packed cell volume (PCV) and urine analysis.

2. Bleeding time (BT), clotting time (CT).

3. Renal function tests, liver function tests.

Hundred pregnant women undergoing LSCS were included in the study. It is a randomised placebo controlled clinical study and every alternate woman was assigned to each of the two groups.

\section{Study Group}

Fifty (50) subjects - Administered with IV tranexamic acid (1 $\mathrm{g} / 10 \mathrm{~mL}$ ) diluted in $20 \mathrm{~mL}$ of $5 \%$ glucose slowly over a period of 5-minute at least 20 minutes prior to the incision of the skin.

\section{Placebo Group}

Fifty (50) subjects received $30 \mathrm{~mL}$ of $5 \%$ glucose. Patient was explained about the administration and safety of placebo and the consent was taken. Intra operatively 5IU of oxytocin was given IV after the delivery of the placenta followed by oxytocin infusion of $10 \mathrm{IU}$ in $500 \mathrm{~mL}$ of normal saline postoperatively along with an antibiotic.

\section{Clinical Observation}

Vitals-Blood pressure (BP), respiratory rate (RR) and heart rate (HR) were measured immediately after the delivery of the placenta and at one and two hours after childbirth respectively. Complete blood picture (CBC), PT, aPTT were recorded before Caesarean section and after $24 \mathrm{hrs}$. Renal function tests and liver function tests were evaluated prior to Caesarean section and $24 \mathrm{hr}$ after delivery to study the adverse effects of TXA. The sheets, as well as the dry and soaked mops used during the Caesarean section were weighed and the mean blood loss was calculated by the formula by Gai. et. al. Blood from sheets and mops $=$ (soaked material weight-dry material weight) / 1.05, (1.05 is specific gravity of blood). To get the total intraoperative blood loss, the blood collected from suction container during delivery was added to the mean blood loss from mops and sheets. Two-hour postoperative blood loss was calculated from the soaked pads by the same formula as above. 


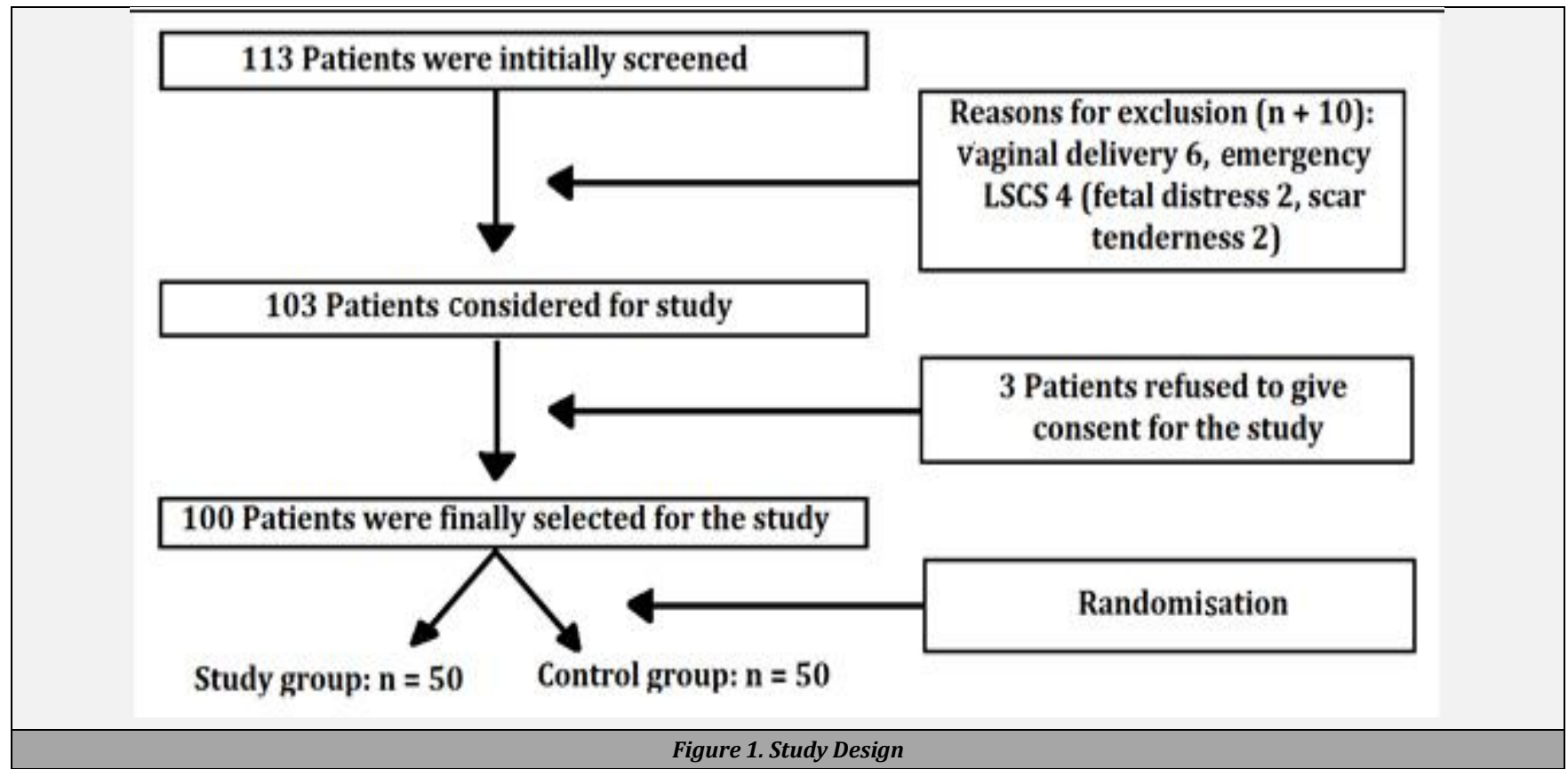

\section{Statistical Analysis}

Quantitative outcome were summarised with mean and standard deviation. Categorical outcome were summarised in percentages. Number variables were compared with independent sample t test, while category variables were dealt with chi square test. Two tailed $\mathrm{P}$ value of $<0.05$ was considered significant. For data analysis, Microsoft Office Excel and SPSS version 21.0 were utilised.

\section{RESULTS}

The results of this study are summarised in 5 tables.

\begin{tabular}{|cccc|}
\hline Parameters & $\begin{array}{c}\text { Study Group } \\
(\mathbf{n}=\mathbf{5 0})\end{array}$ & $\begin{array}{c}\text { Placebo Group } \\
(\mathbf{n}=\mathbf{5 0})\end{array}$ & $\begin{array}{c}\text { P } \\
\text { Value }\end{array}$ \\
Age & $25.00+4.71$ & $25.88+5.39$ & 0.387 \\
Weight & $65.22+5.58$ & $64.86+8.476$ & 0.803 \\
Gravida 1 & $28(56 \%)$ & $31(62 \%)$ & 0.45 \\
2nd & $20(40 \%)$ & $19(38 \%)$ & 0.000 \\
3rd & $2(4 \%)$ & 0 & 0.000 \\
Gestation (weeks) & $38.92+1.38$ & $39.02+1.42$ & 0.722 \\
Parity null & $33(66 \%)$ & $36(72 \%)$ & 0.48 \\
\hline \multicolumn{4}{|r}{ Table 1. Clinical Data of Tranexamic Acid and Placebo Groups } \\
\hline \multicolumn{4}{r}{} \\
\hline
\end{tabular}

Table 1 shows the age, gestational age, weight, gravidity and parity of the pregnant women undergoing Caesarean section in both the groups.

\begin{tabular}{|cccc|}
\hline Vital Signs & Study & Control & P Value \\
\hline Heart rate (bpm) & $86.14+8.35$ & $84.81+835$ & $0.394 \mathrm{NS}$ \\
Respiratory rate (breath / min) & $19.38+2.14$ & $19.94+2.14$ & $0.21 \mathrm{NS}$ \\
\hline Systolic BP (mmhg) & $121.08+10.1$ & $119.81+9.47$ & $0.514 \mathrm{NS}$ \\
\hline Diastolic BP (mmhg) & $77.08+7.04$ & $76.88+7.61$ & $0.892 \mathrm{NS}$ \\
\hline Table 2. Vital Signs at the Time of & \\
Placental Delivery in Both the Groups & \\
\hline
\end{tabular}

Table 2 shows mean heart rate, respiratory rate, systolic blood pressure \& diastolic blood pressure at the time of placental delivery in the study \& control group. There was no statistically significant difference in the vital signs at the time of placental delivery in both the groups.

\begin{tabular}{|cccc|}
\hline Vital Signs & Study & Control & P Value \\
Heart rate (bpm) & $79.96+7.55$ & $82.16+$ & $0.094 \mathrm{NS}$ \\
Respiratory rate (breath / min) & $19.44+2.57$ & $19.58+2.14$ & $0.798 \mathrm{NS}$ \\
Systolic BP (mmHg) & $127.16+12$ & $119.72+11.5$ & $0.647 \mathrm{NS}$ \\
Diastolic BP (mmHg) & $81.04+6.12$ & $78.28+5.39$ & $0.101 \mathrm{NS}$ \\
\hline Table 3. Vital Signs 2 hrs. after Surgery in Both the Groups \\
\hline
\end{tabular}

Table 3 shows mean heart rate, respiratory rate, systolic blood pressure \& diastolic blood pressure at 2 hours after delivery in the study \& control group. There was no significant difference in the vitals in both groups.

\begin{tabular}{|c|c|c|c|c|c|c|c|}
\hline \multicolumn{4}{|c|}{ Preoperative Data } & \multicolumn{4}{|c|}{ Postoperative Data } \\
\hline \multicolumn{2}{|l|}{ Parameters } & $\begin{array}{l}\text { Study } \\
\text { Group }\end{array}$ & $\begin{array}{c}\text { Placebo } \\
\text { Group }\end{array}$ & P1 & $\begin{array}{l}\text { Study } \\
\text { Group }\end{array}$ & $\begin{array}{c}\text { Placebo } \\
\text { Group }\end{array}$ & $\mathbf{P 2}$ \\
\hline \multirow{3}{*}{$\mathrm{Hb}$} & Mean & 10.33 & 9.80 & \multirow{3}{*}{0.050} & 10.08 & 8.81 & \multirow{3}{*}{0.000} \\
\hline & + & + & + & & + & + & \\
\hline & SD & 1.26 & 1.34 & & 1.18 & 1.18 & \\
\hline \multirow{3}{*}{$\begin{array}{l}\text { Platelet } \\
\text { Count }\end{array}$} & Mean & 2.1 & 2.16 & \multirow{3}{*}{0.589} & 1.94 & 2.03 & \multirow{3}{*}{0.493} \\
\hline & + & + & + & & + & + & \\
\hline & SD & 0.62 & 0.62 & & 0.62 & 0.62 & \\
\hline \multirow{3}{*}{ PT } & Mean & 11.86 & 11.87 & \multirow{3}{*}{0.651} & 11.78 & 11.79 & \multirow{3}{*}{0.712} \\
\hline & + & + & + & & + & + & \\
\hline & SD & 0.17 & 0.17 & & 0.16 & 0.16 & \\
\hline \multirow{3}{*}{ APTT } & Mean & 31.53 & 31.51 & \multirow{3}{*}{0.894} & 31.78 & 31.7 & \multirow{3}{*}{0.750} \\
\hline & + & + & + & & + & + & \\
\hline & SD & 0.93 & 0.86 & & 0.91 & 0.83 & \\
\hline \multirow{3}{*}{ ALT } & Mean & 38.34 & 38.92 & \multirow{3}{*}{0.480} & 41.18 & 41.60 & \multirow{3}{*}{0.669} \\
\hline & + & + & + & & + & + & \\
\hline & SD & 4.17 & 3.99 & & 4.95 & 4.8 & \\
\hline \multirow{3}{*}{ AST } & Mean & 39.94 & 38.18 & \multirow{3}{*}{0.212} & 37.8 & 38.78 & \multirow{3}{*}{0.226} \\
\hline & + & + & + & & + & + & \\
\hline & SD & 4.99 & 4.86 & & 4.42 & 4.39 & \\
\hline \multirow{3}{*}{ S. Creatinine } & Mean & 0.80 & 0.79 & \multirow{3}{*}{0.805} & 0.75 & 0.75 & \multirow{3}{*}{0.910} \\
\hline & + & + & + & & + & + & \\
\hline & SD & 0.20 & 0.19 & & 0.17 & 0.16 & \\
\hline \multirow{3}{*}{ S. Urea } & Mean & 22.66 & 22.52 & \multirow{3}{*}{0.655} & 22.08 & 21.96 & \multirow{3}{*}{0.739} \\
\hline & + & + & + & & + & + & \\
\hline & SD & 1.80 & 1.78 & & 1.54 & 1.48 & \\
\hline \multicolumn{8}{|c|}{$\begin{array}{c}\text { Table 4. Comparison between Preoperative and Postoperative PT (s), } \\
\text { aPTT (s), ALT, AST, Serum Creatinine, Serum Urea, Haemoglobin and } \\
\text { Platelet Count in Study and Control Group }\end{array}$} \\
\hline
\end{tabular}

Table 5 shows that both intraoperative and 2-hour postoperative blood loss was significantly less in the study group than the control group. 


\begin{tabular}{|c|c|c|c|}
\hline Parameters & $\begin{array}{l}\text { Study } \\
\text { Group }\end{array}$ & $\begin{array}{l}\text { Control } \\
\text { Group }\end{array}$ & $\begin{array}{c}P \\
\text { Value }\end{array}$ \\
\hline $\begin{array}{l}\text { Volume of blood } \\
\text { in suction (mL) }\end{array}$ & $98.66+28.87$ & $220.81+64.5$ & $\mathrm{P}<0.001$ \\
\hline $\begin{array}{l}\text { Volume of blood in sheets } \\
\quad+\text { mops }(\mathrm{mL})\end{array}$ & $400.10+112.40$ & $470.05+141.07$ & $\mathrm{P}<0.001$ \\
\hline $\begin{array}{l}\text { Intraoperative blood } \\
\text { volume loss }(\mathrm{mL})\end{array}$ & $499.76+111.21$ & $690.85+198.41$ & $\mathrm{P}<0.001$ \\
\hline $\begin{array}{l}2 \text { hrs post-operative } \\
\text { blood volume loss }(\mathrm{mL})\end{array}$ & $59.90+12.6$ & $110.06+13.47$ & $\mathrm{P}<0.001$ \\
\hline Total blood loss & $559.70+113.82$ & $800.91+200.26$ & $\mathrm{P}<0.001$ \\
\hline \multicolumn{4}{|c|}{$\begin{array}{c}\text { Table 5. Intraoperative and Postoperative Blood Loss } \\
\text { in Both Study and Control Groups. }\end{array}$} \\
\hline
\end{tabular}

\begin{tabular}{|cccc|}
\hline Side Effects & Study Group & Placebo Group & P Value \\
Vomiting & $9(18 \%)$ & $8(16 \%)$ & 0.800 \\
Nausea & $16(32 \%)$ & $13(26 \%)$ & 0.058 \\
Sign of thrombosis & 0 & 0 & 0 \\
\hline \multicolumn{4}{|r}{ Table 6. Comparison of Side Effects in Both Groups } \\
\hline
\end{tabular}

\section{DISCUSSION}

TXA exerts its antifibrinolytic effect as it blocks the locus for the lysine binding on the plasmin and plasminogen molecules, thus stopping the binding of plasmin and plasminogen to substract of fibrin. It also prevents the conversion of plasmin from plasminogen. ${ }^{8}$ Post-delivery, temporary activation of the cascade of fibrinolytic for 6 to 10 hours is seen. Hence, TXA is being assessed for its role in preventing post-partum haemorrhage. The results of our study show that pregnant women in the study group had $499.11 \pm 111.2 \mathrm{~mL}$ of mean blood loss and the women of control group had a mean blood loss of $490.85 \pm 298.42 \mathrm{~mL}(\mathrm{P}=0)$. After 2 hours postpartum $59.93 \pm 12 \mathrm{~mL}$ mean loss of blood was seen in study group and $110.16 \pm 13.47 \mathrm{~mL}$ was seen in control group.

In the study performed by "Movafegh. et al,"9 $10 \mathrm{mg} / \mathrm{kg}$ of TXA was administered 20 min before the incision of the skin in Caesarean section. There was less significant mean blood loss in the TXA group when compared to control group, intraoperative bleeding (263.5 \pm 39.7 vs. $405.7 \pm 94.40 \mathrm{~mL})$ and postoperative bleeding ( $67.1 \pm 6.5$ vs. $141.0 \pm 33.9 \mathrm{~mL})$. The significance of administration of oxytocin was also less in the TXA group compared to control group. These results are comparable to present study.

"Gai. et al"10 conducted a similar study in China by administering TXA 10 min before incision. This method earned less bleeding 2 hours post operation $(42.70 \pm 40.40 \mathrm{~mL}$ vs. $73.96 \pm 77.11 \mathrm{~mL}$ ) but there was no significant difference in blood loss after the placental delivery. This may be due to the administration of TXA just 10 min before skin incision. Hence, in our study TXA was administered $20 \mathrm{~min}$ before spinal anaesthesia.

Ferrer et al has found three trials which were randomised controlled trials and they were conducted involving 461 participants. Out of these trials, there were two who had csection "delivery"11,10 and one had normal vaginal "delivery.12" After combining the results of all three trials it was found that tranexamic acid reduced the mean blood loss significantly by $92 \mathrm{~mL}$ compared to non-treated individuals. There was no report of mortality and thrombotic event.

In our study, postoperatively, there was no significant difference in pulse rate (PR), systolic blood pressure (SBP), diastolic blood pressure (DBP), and RR in the two groups. In the study by "Movafegh et al." 9 and "Gai et al".,10 there was no difference in any of the postoperative vital signs.

There was significant difference in postoperative haemoglobin levels in between the two groups, mean concentration being $10.0 \mathrm{~g} \%$ in the study group versus $8.8 \mathrm{~g}$ $\%$ in the control group $(\mathrm{P}=0.000)$. There was no significant difference between the preoperative and postoperative haemoglobin values in the study group than the control group ( $\mathrm{P}$ value $=0.000)$.

There were no significant changes in complete blood count, prothrombin time, aPTT, liver function test (LFT) and renal function test (RFT) after TXA treatment, this was not consistent with "Baird EJ"13 "Bresnoc et al,"14 Gai, "Gohel et al,"15 "Sekhavat et al,"16 "Yang et al,"12 There was 5 - 6 fold increase in risk of thrombotic events in pregnant women compared to non-pregnant women, and are more common in the post-delivery after Caesarean section in women who were given TXA. The appearance of TXA in the cord blood is almost the same value as in mothers blood as TXA will cross the placenta. TXA will also appear in the breast milk in a very low amount, i.e.; 1 / 100th of the amount seen in blood of the mother. Increased incidence of thrombotic events was seen in patients, even after treatment with antifibrinolytic agents but there is no statistically significant increase in patients treated with "tranexamic acid."17

"Svanberg et al"18 conducted a study in which 67 cases were treated by tranexamic acid I / v / o abruptio placenta, no thrombosis was reported or any other side effects like diarrhoea, vomiting, nausea were seen. Bekarsy and "Astedt"19 conducted a study on 3014 women in whom 45 women were pregnant and were given tranexamic acid to stop bleeding during conisation of cervix, there were no thromboembolic episodes or side effects. "Baird EJ13" conducted a study on 400 women who were pregnant and had spontaneous vaginal delivery, we're given tranexamic acid during labour, no thrombotic events or side effects were reported. These results are comparable to the results seen in study of "Gohel et al,"15 "Sekhavat et al,"16 "Gai et al,"10

\section{CONCLUSIONS}

A safe dose of IV tranexamic acid prior to Caesarean section has an effective role in reducing blood loss without causing any side effects.

Data sharing statement provided by the authors is available with the full text of this article at jemds.com.

Financial or other competing interests: None.

Disclosure forms provided by the authors are available with the full text of this article at jemds.com.

\section{REFERENCES}

[1] Shakur H, Elbourne D, Gulmezoglu M, et al. The woman trial (World Maternal Antifibrinolytic Trial): tranexamic acid for the treatment of postpartum haemorrhage: an international randomised, double blind placebo controlled trial. Trials 2010;11:40.

[2] AbouZahr C. Antepartum and postpartum haemorrhage. Chap - 4. $1^{\text {st }}$ edn. Boston (United States of America) 
Geneva (Switzerland): Harvard School of Public Health on behalf of the World Health Organisation and the World Bank 1998.

[3] Magann EF, Evans S, Hutchinson M, et al. Postpartum haemorrhage after cesarean delivery: an analysis of risk factors. South Med J 2005;98(7):681-5.

[4] Munn MB, Owen J, Vincent R, et al. Comparison of two oxytocin regimens to prevent uterine atony at cesarean delivery: a randomized controlled trial. Obstet Gynecol 2001;98(3):386-90.

[5] Hofmeyr GJ, Walraven G, Gulmezoglu AM, et al. Misoprostol to treat postpartum haemorrhage: a systematic review. BJOG 2005;112(5):547-53.

[6] Weeks A. The prevention and treatment of postpartum haemorrhage: what do we know and where do we go to next? BJOG 2015;122(2):202-10.

[7] World Health Organization. WHO recommendations for the prevention and treatment of postpartum haemorrhage. WHO, 2012.

[8] Thorsen S, Clemmenson I, Sottrup-Jensen L, et al. Adsorption to fibrin of native fragments of known primary structure from human plasminogen. Biochim Biohys Acta 1981;668(3):377-87.

[9] Movafegh A, Eslamian L, Dorabadi A. Effect of intravenous tranexamic acid administration on blood loss during and after caesarean delivery. Int J Gynaecol Obstet 2011;115(3):224-6.

[10] Gai MY, Wu LF, Su QF, et al. Clinical observation of blood loss reduced by tranexamic acid during and after caesarian section: a multi-center, randomized trial. Eur J Obstet Gynecol Reprod Biol 2004;112(2):154-7.
[11] Katsaros D, Petricevic M, Snow NJ, et al. Tranexamic acid reduces postbypass blood use: a double-blinded, prospective, randomized study of 210 patients. Ann Thorac Surg 1996;61(4):1131-5.

[12] Yang H, Zheng S, Shi C. Clinical study on the efficacy of tranexamic acid in reducing postpartum blood loss: a randomized, comparative, multicenter trial. Zhonghua Fu Chan Ke Za Zhi 2001;36(10):590-2.

[13] Baird EJ. Identification and management of obstetric hemorrhage. Anesthesiol Clin 2017;35(1):15-34.

[14] Bresnoc. Tranexamic acid in postpartum hemorrhage. $\mathrm{Br}$ J Obstet Gynecol 1996;102(12):1250-1.

[15] Mayur G, Purvi P, Ashoo G, et al. Efficacy of tranexamic acid in reducing blood loss during and after the lower segment cesarean section. A randomized case controlled prospective study. J Obstet Gynecol India 2007;50:22730.

[16] Sekhavat L, Tabatabaii A, Dalili M, et al. Efficacy of tranexamic acid in reducing blood loss after cesarean section. J Matern Fetal Neonatal Med 2009;22(1):72-5.

[17] Henry DA, Carless PA, Moxey AJ, et al. Anti-fibrinolytic use for minimizing perioperative allogeneic blood transfusion. Cochrane Database Syst Rev 2001;19(1):CD001886.

[18] Svanberg L, Astedt B, Nilsson IM, et al. Abruptio placentae--treatment with the fibrinolytic inhibitor tranexamic acid. Acta Obstet Gynecol Scand 1980;59(2):127-30.

[19] Bekassy Z, Astedt B. Treatment with the fibrinolytic inhibitor tranexamic acid--risk for thrombosis. Acta Obstet Gynecol Scand 1990;69(4):353-4. 